\title{
Analisis Vidio Likes to Followers Ratio InstagramPada 5 Brand Fashion Lokal Yang Mendunia
}

\author{
I Kadek Agus Dwiandika \\ dwiandika.agus@gmail.com
}

\begin{abstract}
Instagram is a photo sharing application that applies digital filters and shares them via social networking services. Communication between Instagram users can be established by liking and commenting on photos uploaded by other users. Instagram is in great demand by almost all circles. As one of the social media loved by the Indonesian people who can share photo content. By accessing Instagram, it will be an exciting activity favored by Indonesian internet users. It is not surprising that online businesses are starting to use Instagram to expand their business. This study uses a quantitative exploratory method to determine the credibility of the performance of 5 global local fashion brand Instagram accounts. Explorative research is a type of social research whose purpose is to provide a little definition or explanation of the concepts or patterns used in the research. From the Table of Account Ratio Values for 5 Global Local Fashion Brands, it can be concluded that Erigo Store gets the highest score for the ratio of Video Likes. to Followers Ratio. While the Instagram account Casteyewear got the lowest score for this ratio. So, in this study, Erigo Store has better credibility than other brands..
\end{abstract}

\begin{abstract}
ABSTRAK
Instagram adalah aplikasi berbagi foto yang menerapkan filter digital dan membagikannya melalui layanan jejaring sosial. Komunikasi antar pengguna Instagram dapat terjalin dengan menyukai dan mengomentari foto yang diunggah oleh pengguna lainnya. Instagramsangat diminati hampir dari semua kalangan. Sebagai salah satu dari media sosial yang digandrungimasyarakat Indonesia yang dapat membagikan konten foto. Dengan mengakses Instagram, maka akan menjadi aktivitas seru yang disukai oleh pengguna internet Indonesia. Tidak mengherankan bahwa para pebisnis online mulai memanfaatkan instagram untuk mengembangkan usahanya. Penelitian ini menggunakan metode eksploratif kuantitatif untuk mengetahui kredibilitas dari performa 5 akun Instagram brand fashion lokal yang mendunia. Penelitian eksploratif adalah salah satu jenis penelitian sosial yang tujuannya untuk memberikan sedikit definisi atau penjelasan mengenai konsep atau pola yang digunakan dalam penelitian Dari Tabel Nilai Rasio Akun Instagram 5 Brand Fashin Lokal Yang Mendunia, dapat di simpulkan bahwa Erigo Store mendapatkan nilai tertinggi untuk rasio Video Likes to Followers Ratio. Sedangkan akun Instagram Casteyewear mendapatkan nilai terendah untuk rasio ini. Jadi, pada penelitian ini Erigo Store memiliki kredibilitas performa yang lebih baik dibandingkan dengan Brand lainnya.
\end{abstract}

Keyword : Sosial Media Instagram ; credibility account Instagram ; Vidio Likes to followers Ratio ; Brand Fashion Lokal 


\section{PENDAHULUAN}

Perkembangan teknologi informasi membawa dampak yang besar di segala bidang kehidupan. Selain pendidikan untuk memajukan kegiatan pendidikan dan pembelajaran, teknologi informasi juga digunakan sebagai strategi bisnis untuk menghasilkan keuntungan. Kehadiran perkembangan digital dan teknologi internet menawarkan peluang besar bagi banyak bisnis dan usaha kecil umkm. Teknologi tidak hanya memudahkan kita untuk bersosialisasi, tetapi juga memudahkan kita dalammenjalankan bisnis. Dari perspektif manajemen, produksi, atau layanan pengiriman, ada berbagai platform yang membantu bisnis yang dijalani tetap berjalan dengan lancar.(Optimalisasi InstagramSebagai Media Marketing: Potret Penggunaan Instagram ... Irfan Ardiansah, Anastasya Maharani - Google Buku, n.d.).

Salah satu media sosial paling populer dan salah satu fitur hebat di smartphone adalah Instagram. Instagram adalah aplikasi berbagi foto yang menerapkan filter digital dan membagikannya melaluilayanan jejaring sosial. Komunikasi antar pengguna Instagram dapat terjalin dengan menyukai dan mengomentari foto yang diunggah oleh pengguna lainnya. Instagramsangat diminati hampir dari semua kalangan. Sebagai salah satu dari media sosial yang digandrungimasyarakat Indonesia yang dapat membagikan konten foto. Dengan mengakses Instagram, maka akan menjadi aktivitas seru yang disukai oleh pengguna internet Indonesia. Tidak mengherankan bahwa para pebisnis online mulai memanfaatkan instagram untuk mengembangkan usahanya (Miranda et al., 2017)

Secara global, Instagram berperan utama dalam menarik konsumen untuk lebih dekat dangan apa yang mereka sukai, termasuk dari berbagai usaha kecil dan menengah (UMKM), yang sesuai denganminat mereka. Saat ini, Instagram dikenal sebagai salah satu media bisnis yang paling banyak digunakan di Indonesia Meningkatnya jumlah pengguna Instagram di Indonesia tentu dapat memberikan peluang bagi brand untuk menjadikan platform ini sebagai platform social media marketing. Cukup banyak akun perushaan-perusahaan terkenal yang ada pada Instagram , contohnya seperti Brand fashion local Indonesia yang mendunia. Adapun Top 5 Brand Fashion Lokal Yang Mendunia, diantaranya yaitu : Erigo Store, Buttonscarves, Elhaus, Matoa Indonesia, Casteyewear (7 Brand Fashion Lokal Indonesia Yang Mendunia|BukaReview, n.d.)

Peningkatan Pengguna Instagram, membuat peneliti ingin melakukan tinjauan kualitatif terhadap akun yang ada di media sosial Instagram. Terdapat 2 rasio yang ada pada sosial media Instagram dan relevan digunakan sebagai media ukur kredibilitas akun yang ada. Penelitian ini hanya berfokusuntuk menghitung kredibilitas Analisis Vidio Likes to Followers Ratio Instagram Pada 5 Brand Fashion Lokal Yang Mendunia. Tujuan dari penelitian ini adalah mengetahui kredibilitas performa dari akun 5 Brand Fashion Lokal Yang Mendunia menggunakan Video Likes dan Followers Ratio.(View of Analisis Rasio Pada Instagram Untuk Penelitian Kualitatif Menggunakan Metode Ekploratif, n.d.)(View of Analisis Rasio Pada Instagram Untuk Penelitian Kualitatif MenggunakanMetode Ekploratif, n.d.).

\section{TINJAUAN PUSTAKA}

Perkembangan Teknologi dari waktu ke waktu semakin berkembang, dengan semakin berkembangnya teknologi dan ditambah adanya pandemi saat ini, teknologi sangat dibutuhkan untuk membantu manusia dari keterbatasan yang tercipta karena pandemi. Berbagai aplikasi dan platform media sosial semakin banyak akibat pandemi saat ini, diantaranya Facebook, Whatsapp, Instagram dan berbagai aplikasi media sosial lainnya. Menurut data yang didapat 
instagram menduduki pringkat ketiga dengan pengguna yang meningkat dan menggeser peringkat pengguna facebook di tahun ini(Data: Ini Media Sosial Paling Populer Di Indonesia2020-2021, n.d.).

Instagram adalah sosial media berbasis gambar yang memberikan layanan berbagi foto atau video secara online. Instagram berasal dari pengertian dari keseluruhan fungsi aplikasi ini. Kata "insta" berasal dari kata "instan", seperti kamera polaroid yang pada masanya lebih dikenal dengan sebutan "foto instan". Instagram juga dapat menampilkan foto-foto secara instan, sepertipolaroid didalam tampilannya. Sedangkan untuk kata "gram" berasal dari kata "telegram" yangcara kerjanya untuk mengirimkan informasi kepada orang lain dengan cepat. Sama halnya dengan Instagram yang dapat mengunggah foto dengan menggunakan jaringan Internet, sehingga informasi yang ingin disampaikan dapat diterima dengan cepat. Oleh karena itulah Instagram merupakan lakuran dari kata instan dan telegram( $\underline{\text { htp://eprints.umm.ac.id/43019/5) }}$.

Kegunaan instagram tidak hanya untuk membagikan vidio dan foto, tetapi aplikasi Instagram juga berfungsi sebagai media untuk mencari penghasilan, bahkan menjadi pekerjaan utama. Beberapa cara yang dapat di lakukan agar mendapatkan uang dari Instagram adalah dengan menjualproduk, menawarkan jasa, endorse, menjual foto, mencari sponsor dan ada jugayang menjual akunInstagram itu sendiri(7 Kegunaan Lain Instagram Selain Pamer Foto Dan Video | Muh-Amin.Com,n.d.)

Instagram sangat memberikan pengaruh dalam industri, kredibiltas akun instagram merupakan suatu hal yang cukup penting untuk berbagai kepentingan. kredilitas akun instagramdapat di ukur dari tingkat performa yang dihasilkan secara sistematis. Dalam mengukur performa diperlukan sekala pengukuran yang tertuang ke dalam rasio.

\section{METODE}

Penelitian ini menggunakan metode eksploratif kuantitatif untuk mengetahui kredibilitas dari performa 5 akun Instagram brand fashion lokal yang mendunia. Penelitian eksploratif adalah salah satu jenis penelitian sosial yang tujuannya untuk memberikan sedikit definisi atau penjelasan mengenai konsep atau pola yang digunakan dalam penelitian (Penelitian Eksploratif - Wikipedia Bahasa Indonesia, Ensiklopedia Bebas, n.d.)

Tujuan dari penelitian ini adalah untuk mengetahui nilai kredibillitas dari performa akun Instagram brand fashion lokal yang mendunia. Dalam penelitian ini, ada beberapa langkah yang perlu di lakukan untuk menentukan akun brand fashion lokal yang mendunia. Langkah-langkah yang dilakukan dalam penelitian ini adalah sebagai berikut :

\section{Melakukan Eksplorasi Pada Website Untuk Menentukan Objek yang Akan Dianalisa.}

Survei ini dilakukan pada beberapa website yang menyediakan informasi tentang objek yang disurvei. Ketika survei selesai, Maka hasil survei meneumkan nama-nama brand fashion lokalyang mendunia untuk dianalisis. Setelah melakukan pencarian di halaman website, langkahselanjutnya adalah mencari nama dari masing-masing akun Instagram brand fashion lokalyang mendunia, dan Pastikan semua penyedia memiliki akun di media sosial Insatagram. 


\section{Menghitung Nilai Rata-Rata Variable Dari Top 5 Brand Fashion Lokal Yang}

Mendunia.

Pada langkah ini, peneliti menghitung nilai Variabel Video Likes dan Followers Akun dari masing- masing akun Instagram. Variabel merupakan sesuatu yang memiliki nilai bervariasi dimana nilai tersebut dapat dijadikan sebagai dasar untuk empat data yang berbeda seperti rasio, skala,ordinal, nominal dan internal (Rankuti 2015). Untuk menghitung nilai rata-rata dari variabel Video Likes dan Followers Akun dengan cara mengambil 10 postingan di setiapakun, kemudian di hitung sehingga menemukan nilai rata-rata dari masing-masing variabel.

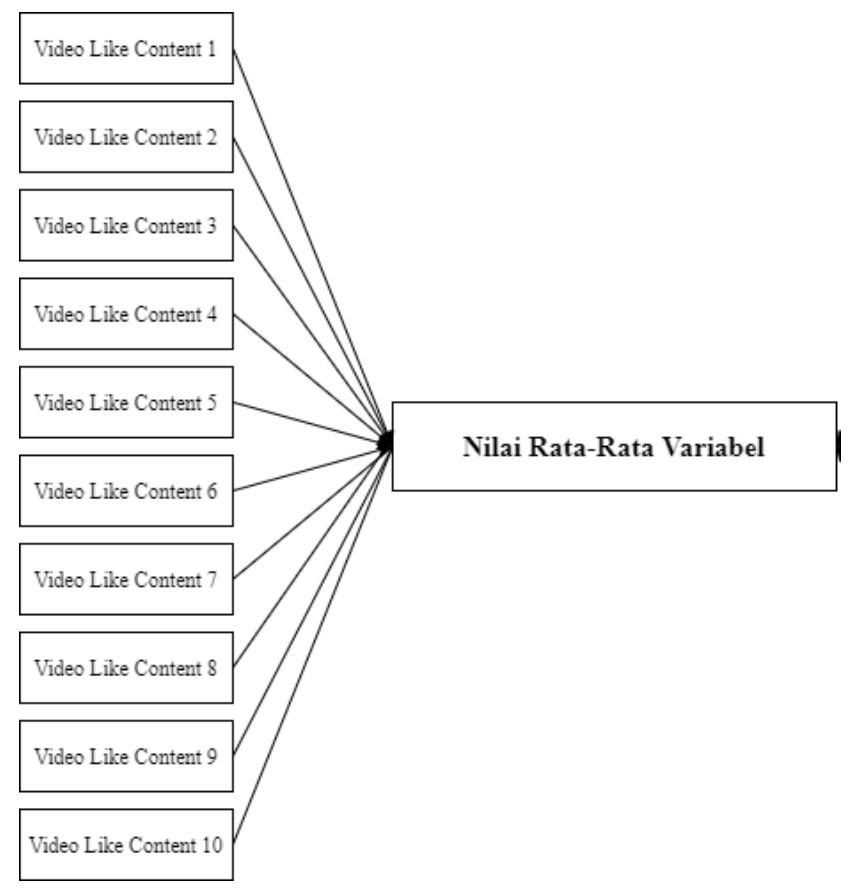

Gambar 1. Analisa Nilai Rata-Rata Variabe

\section{Menghitung Nilai Kredibilitas Rasio}

Untuk menghitung nilai kredibilitas dari Video Likes dan Followers Akun Instagram, penelitimenggunakan cara pembagian nilai variable pertama dengan variable kedua. Jika video likesmemiliki nilai 100 dan Follewers akun Instagram mempunyai nilai 300, maka dapat menghitungnya dengan cara $100: 300=0,3$. Dengan begitu hasil yang di dapat dari Video Likes dan Followers Akun Instagram adalah 0,3.

\section{Menentukan Peringkat Pada Akun Instagram}

Langkah terakhir dalam penelitian ini adalah menentukan peringkat setiap rasio yang ada. Saat menentukan peringkat, kita perlu mempertimbangkan karakteristik rasio yang diselidiki. Jika karakteristik rasio rendah maka objek yang memiliki nilai terendah akan mendapat nilai 5 dan objek yang memiliki nilai tertinggi akan mendapatkan nilai 1. Jika rasio memiliki karakteristiktiggi maka objek memiliki nilai tinggi akan mendapatkan angka 5 dan objek yang mendapatkan nilai rendah mendapatkan nilai 1, Setelah mendapatkan hasil rasio, Anda dapatmenyimpulkan objek mana yang mendapatkan nilai 1 hingga 5 .

\section{HASIL DAN PEMBAHASAN}

Akun Instagram dari 5 Brand Fashion Lokal Yang Mendunia, diantaranya : 


\section{Erigo Store}

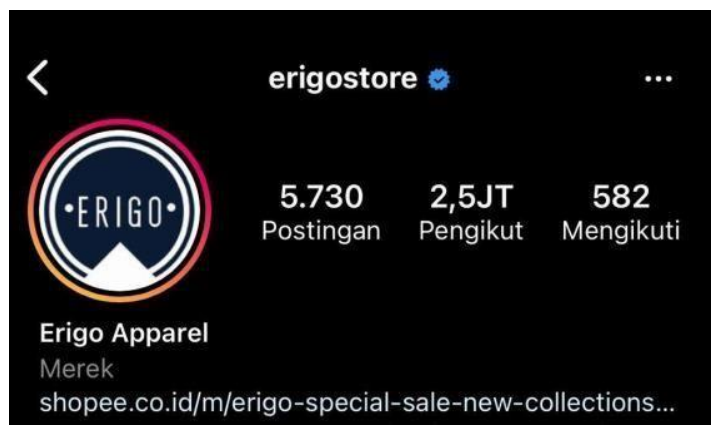

Gambar 1. Akun Instagram erigostore

Sumber $:$ https://instagram.com/erigostore?utm_medium=copy_link

\section{Buttonscarves}

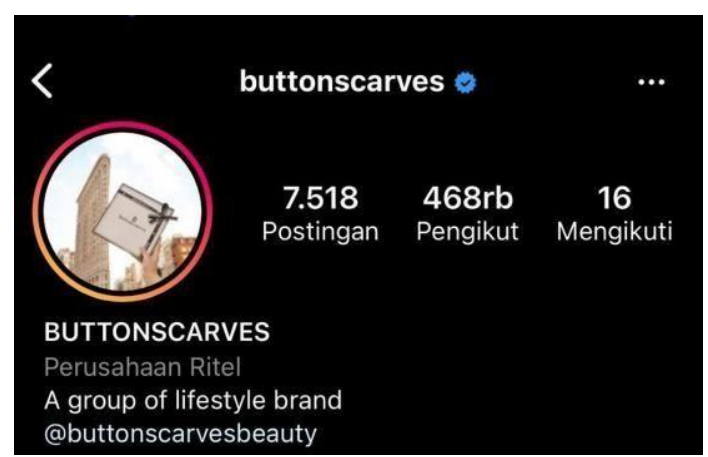

Gambar 2. Akun Instagram Buttonscarves

Sumber : https://instagram.com/buttonscarves?utm medium=copy_link 


\section{Elhaus}

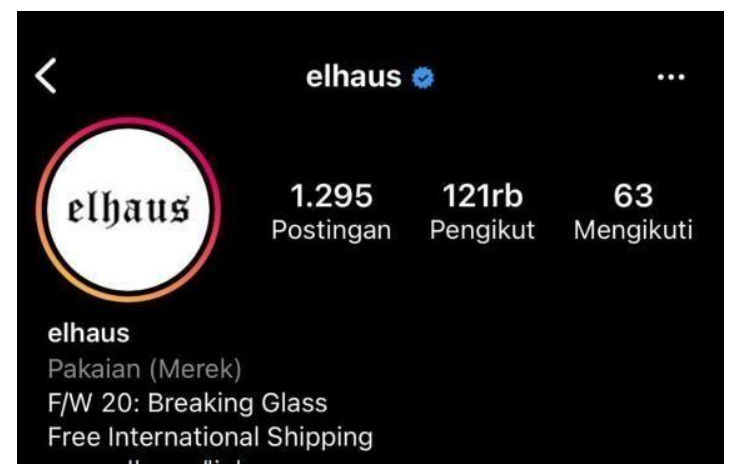

Gambar 3. Akun Instagram Elhaus

Sumber $: \underline{\text { https://instagram.com/elhaus?utm_medium=copy_link }}$

\section{Matoa Indonesia}

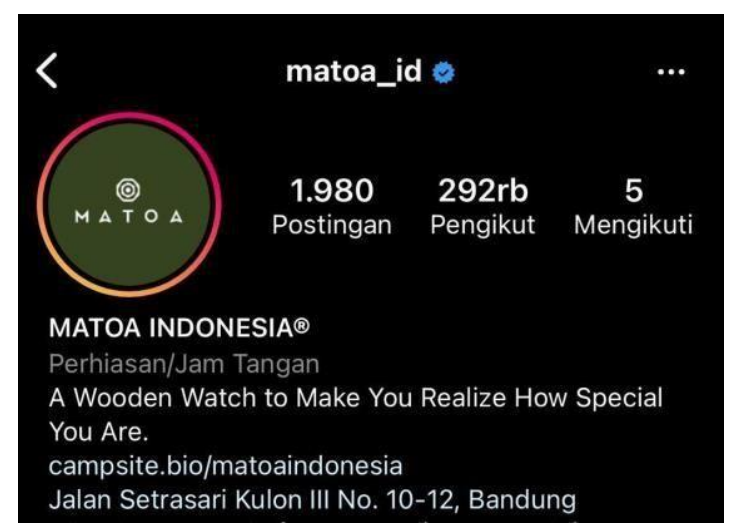

Gambar 4. Akun Instagram Matoa Indonesia

Sumber $: \underline{\text { https://instagram.com/matoa_id?utm_medium=copy_link }}$

\section{Casteyewear}

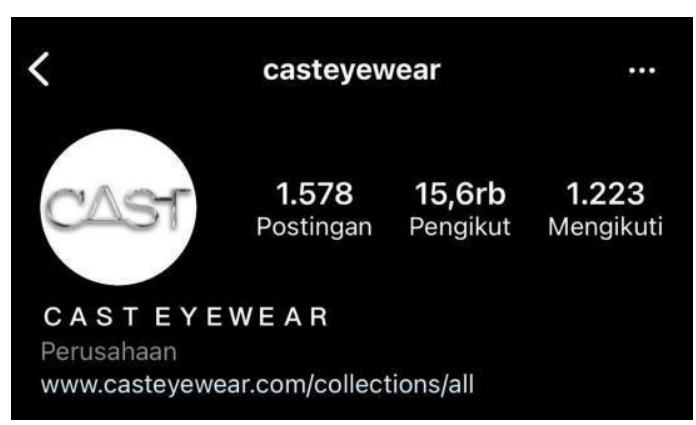

Gambar 5. Akun Instagram Casteyewear

Sumber $: \underline{\text { https://instagram.com/casteyewear?utm_medium=copy_link }}$ 
Dari kelima akun Instagram 5 Brand Fashion Lokal Yang Mendunia, peneliti menemukan nilaidari masing-masing variabel yang ada untuk menghitung rasio Video Comments to VideoViewsdari setiap akun. Pada akun TikTok terdapat 2 variabel, diantaranya yaitu :

\section{Vidio likes}

2. Followers Ratio

Peneliti hanya fokus untuk menemukan hasil dari 2 variabel, yaitu :

1. Video Likes

\section{Followers Ratio}

Dari kedua variabel tersebut kemudian dianalisa sehingga menemukan nilai rata-rata dari variabel video Likes dan variabel Followers Ratio . Untuk menghitung nilai rata-rata dari keduavariabel, maka yang dilakukan dengan cara mengambil minimal 10 postingan kemudian di hitung sehingga menemukan nilai rata-rata dari masing-masing variabel. Berikut merupakan tabel nilai rata-rata dari masing-masing Brand Fashion Lokal Yang Mendunia, yaitu :

Tabel 1. Analisa Nilai Rata-Rata Nilai Variabel Video Likes dan Followers Akun Instagram erigo store

\section{Erigo Store}

\begin{tabular}{|c|c|c|}
\hline \multicolumn{1}{|l|}{ No } & Vidio Likes & Followers \\
\hline 1 & 2.372 & 2.500 .000 \\
\hline 2 & 5.843 & \\
\hline 3 & 4.492 & \\
\hline 4 & 2.396 & \\
\hline 5 & 4.251 & \\
\hline 6 & 7.559 & \\
\hline 7 & 2.373 & \\
\hline 8 & 4.495 & \\
\hline 9 & 7.560 & \\
\hline 10 & 8.836 & \\
\hline Rata-rata & 5.018 & 2.500 .000 \\
\hline
\end{tabular}

Sumber : Pengolah Data Excel 
Tabel 2. Analisa Nilai Rata-Rata Nilai Variabel Video Likes dan Followers AkunInstagram Buttonscarves

\section{Buttonscarves}

\begin{tabular}{|c|c|c|}
\hline No & Vidio Likes & Followers \\
\hline 1 & 1.135 & 462.000 \\
\hline 2 & 1.172 & \\
\hline 3 & 267 & \\
\hline 4 & 599 & \\
\hline 5 & 356 & \\
\hline 6 & 564 & \\
\hline 7 & 516 & \\
\hline 8 & 1.202 & \\
\hline 9 & 777 & \\
\hline 10 & 2.177 & \\
\hline Rata-rata & 877 & 462.000 \\
\hline
\end{tabular}

Sumber : Pengolah Data Excel

Tabel 3. Analisa Nilai Rata-Rata Nilai Variabel Video Likes dan Followers Akun Instagram Elhaus

Elhaus

\begin{tabular}{|c|c|c|}
\hline No & Vidio Likes & Followers \\
\hline 1 & 4 & 121.000 \\
\hline 2 & 135 & \\
\hline 3 & 122 & \\
\hline 4 & 0 & \\
\hline 5 & 0 & \\
\hline 6 & 0 & \\
\hline 7 & 0 & \\
\hline 8 & 0 & \\
\hline 9 & 0 & \\
\hline 10 & 0 & \\
\hline Rata-rata & 26,1 & 121.000 \\
\hline
\end{tabular}

Sumber : Pengolah Data Excel 
Tabel 4. Analisa Nilai Rata-Rata Nilai Variabel Video Likes dan Followers AkunInstagram Matoa Indonesia

Matoa Indonesia

\begin{tabular}{|c|c|c|}
\hline No & Vidio Likes & Followers \\
\hline 1 & 747 & 291.000 \\
\hline 2 & 0 & \\
\hline 3 & 0 & \\
\hline 4 & 0 & \\
\hline 5 & 0 & \\
\hline 6 & 0 & \\
\hline 7 & 0 & \\
\hline 8 & 0 & \\
\hline 9 & 0 & \\
\hline 10 & 0 & \\
\hline Rata-rata & 74,7 & 291.000 \\
\hline
\end{tabular}

Sumber : Pengolah Data Excel

Tabel 5. Analisa Rata-Rata Nilai Variabel Video Likes dan Followers Akun Instagram

Casteyewear

\begin{tabular}{|c|c|c|}
\hline \multicolumn{1}{|l|}{ No } & Vidio Likes & Followers \\
\hline 1 & 0 & 15.700 \\
\hline 2 & 0 & \\
\hline 3 & 0 & \\
\hline 4 & 0 & \\
\hline 5 & 0 & \\
\hline 6 & 0 & \\
\hline 7 & 0 & \\
\hline 8 & 0 & \\
\hline 9 & 0 & \\
\hline 10 & 0 & \\
\hline Rata-rata & 0 & 15.700 \\
\hline
\end{tabular}

Sumber : Pengolah Data Excel 
Setelah menghitung nilai rata-rata tersebut, maka akan menemukan hasil akhir nilai rataratadari variabel video Likes dan Followers.

Tabel 6. Nilai Variabel Pada Akun Instagram 5 Brand Fashion Lokal Yang mendunia.

\begin{tabular}{|l|c|c|c|c|c|}
\hline \multicolumn{7}{|c|}{$\begin{array}{c}\text { Tabel Nilai Masing-masing } \\
\text { Variabel }\end{array}$} \\
\hline Variable & Erigo Store & Buttonscarves & Elhaus & Matoa Indonesia & Casteyewear \\
\hline Vidio Likes & 5.018 & 877 & 26 & 747 & 0 \\
& & & 1 & & 15.700 \\
\hline Followers Ratio & 2.500 .000 & 462.000 & 121.000 & 291.000 & \\
\hline
\end{tabular}

Sumber : Pengolah Data Excel

Untuk menghitung kredibilitas dari masing-masing akun Instagram setiap Brand Fashion Lokal , peneliti menghitung dengan cara : variabel 1 akan dibagi dengan variabel 2 , sehingga ditemukan hasil analisisa dari rasio tersebut.

Tabel 7. Hasil Perhitungan Rasio Akun Instagram

\begin{tabular}{|c|c|c|c|c|c|c|c|}
\hline \multicolumn{7}{|c|}{ Tabel Rasio } & \\
\hline $\begin{array}{l}\mathrm{N} \\
\mathrm{O}\end{array}$ & Ratio & Erigo Store & $\begin{array}{l}\text { Buttonscarve } \\
\text { s }\end{array}$ & Elhaus & $\begin{array}{l}\text { Matoa } \\
\text { Indonesia }\end{array}$ & $\begin{array}{l}\text { Casteyewea } \\
\mathrm{r}\end{array}$ & $\begin{array}{c}\text { Karakterist } \\
\text { ik }\end{array}$ \\
\hline 1 & Analisis Vidio Likes to Followers Ratio Instagram & $\begin{array}{l}0,00200 \\
72\end{array}$ & 0,001898268 & 0,002157025 & 0,00256701 & 0 & Tinggi \\
\hline
\end{tabular}

Sumber : Pengolah Data Excel

Video Likes to Followers Ratio memiliki karakteristik yang tinggi, artinya semakin tinggi nilai yang dihasilkan maka semakin baik kredibilitas dari performa akun tersebut. Untuk memberikan peringkat pada masing-masing Brand Fashion, peneliti memberikan angka 1 kepada Brand yang mendapatkan nilai tertinggi, dan angka 5 untuk Brand Fashion yang mendapatkan nilai terendah. Berikut merupakan tabel urutan nilai yang dihasilkan oleh masingmasing vendor smartphone.

Tabel 8. Nilai Rasio Pada Akun Instagram 5 Brand Fashion Lokal Yang Mendunia.

\begin{tabular}{|c|c|c|c|c|}
\hline \multicolumn{5}{|c|}{ Tabel Peringkat } \\
\hline Erigo Store & Buttonscarves & Elhaus & Matoa Indonesia & Casteyewear \\
\hline 1 & 4 & 3 & 2 & 5 \\
\hline
\end{tabular}

Sumber : Pengolah Data Excel

Dari Tabel Nilai Rasio Akun Instagram 5 Brand Fashin Lokal Yang Mendunia, dapat di simpulkan bahwa Erigo Store mendapatkan nilai tertinggi untuk rasio Video Likes to Followers Ratio. Sedangkan akun Instagram Casteyewear mendapatkan nilai terendah untuk rasio ini. Jadi, pada penelitian ini Erigo Store memiliki kredibilitas performa yang lebih baik dibandingkan dengan Brand lainnya. 


\section{KESIMPULAN}

Tujuan dari penelitian ini adalah mengetahui kredibilitas performa dari akun Instagram 5 Brand Fashion Lokal Yang Mendunia menggunakan Video Likes to Followers Ratio. 5 Brand Fashion Lokal Yang Mendunia tersebut diantaranya : Erigo Store, Buttonscarves, Elhaus, Matoa Indonesia, Casteyewear. Dari kelima Brand tersebutv dapat disimpulkan bahwa :

Analisis Vidio Likes to Followers Ratio Instagram :

Pringkat :

Pringkat Pertama : Erigo Store

Pringkat Kedua : Matoa Indonesia

Peringkat Ketiga : Elhaus

Peringkat Empat : Buttonscarves

Peringkat lima : Casteyewear 


\section{DAFTAR PUSTAKA}

(Menentukan Ukuran Post Instagram Dengan Tepat, n.d.)

(7 Brand Fashion Lokal Indonesia Yang Mendunia|BukaReview, n.d.)

(7 Kegunaan Lain Instagram Selain Pamer Foto Dan Video | MuhAmin.Com, n.d.)

(Data: Ini Media Sosial Paling Populer Di Indonesia 2020-2021, n.d.)

(Miranda et al., 2017)

(Optimalisasi Instagram Sebagai Media Marketing: Potret Penggunaan Instagram ... - Irfan Ardiansah, Anastasya Maharani - Google Buku, n.d.)

(Media Sosial: Pengertian, Dampak, Jenis, Dan Manfaat Bagi Bisnis, n.d.)(View of Analisis Rasio Pada Instagram Untuk Penelitian Kualitatif Menggunakan Metode Ekploratif, n.d.)

(View of Analisis Rasio Pada Instagram Untuk Penelitian Kualitatif Menggunakan Metode Ekploratif, n.d.)(View of Analisis Rasio Pada Instagram Untuk Penelitian Kualitatif Menggunakan Metode Ekploratif, n.d.)

(Manfaat Teknologi Informasi Di Berbagai Bidang, Memudahkan Kehidupan Manusia Halaman 3 | Merdeka.Com, n.d.) 
